\title{
Fluid cushion protects against thermal damage during argon plasma coagulation
}

\section{Roberta Masellia,b, Paul J. Belletrutti ${ }^{b}$, Marco Spadaccinia, ${ }^{a, b}$, Piera Alessia Galteri ${ }^{b}$, Thomas Stäblerc, Michael Edererc, Alexander Neugebauerc, Markus D. Enderlec, Alessandro Repicia,b}

Humanitas University, Milan, Italy; Humanitas Clinical and Research Center IRCCS, Rozzano, Italy; Erbe Elektromedizin GmbH, Tubingen, Germany

\section{Abstract}

${ }^{a}$ Department of Biomedical Sciences, Humanitas University, Milan, Italy (Roberta Maselli, Marco Spadaccini, Alessandro Repici);

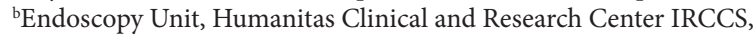
Rozzano, Italy (Roberta Maselli, Paul J. Belletrutti, Marco Spadaccini, Piera Alessia Galteri, Alessandro Repici); ${ }^{\circ}$ Research Department Erbe Elektromedizin GmbH, Tubingen, Germany (Thomas Stäbler, Michael Ederer, Alexander Neugebauer, Markus D. Enderle)

Conflict of Interest: Roberta Maselli, Paul J. Belletrutti, Marco Spadaccini, Piera Alessia Galteri, Milena Di Leo and Alessandro Repici have no conflicts of interest or financial ties to disclose; Thomas Stäbler, Michael Ederer, Alexander Neugebauer, Markus D. Enderle are employees at the Research Department of Erbe Elektromedizin GmbH

Correspondence to: Marco Spadaccini, MD, Digestive Endoscopy Unit, Humanitas Research Hospital, Via Manzoni 56, 20089 Rozzano, Milano, Italy, e-mail: marcospadaccini9@gmail.com

Received 27 February 2021; accepted 16 June 2021; published online 14 September 2021

DOI: https://doi.org/10.20524/aog.2021.0667

\section{Introduction}

Compared to other modalities, argon plasma coagulation (APC) has been established as a very safe thermocoagulative option in the gastrointestinal (GI) tract. APC has a wide range of clinical applications in a variety of GI conditions, including the destruction of superficial neoplasia, treatment of active and chronic mucosal hemorrhage, elimination of GI tract angiodysplasias, and debulking of tissue overgrowth into luminal stents. Mucosal application of APC results in a uniform area of cellular desiccation, coagulation and devitalization at a limited depth, dependent on the duration of ablation and the power setting employed [1].

Serious adverse events related to APC, namely major bleeding and GI tract perforation, are rare, with an incidence of less than $1 \%$ according to the literature $[2,3]$. Luminal strictures can also occur after wide-field APC ablation, for example in 
the treatment of gastric antral vascular ectasia or Barrett's esophagus [4-6]. In clinical practice, deep ulcers can sometimes be observed at follow-up endoscopy after APC ablation. These complications suggest that APC can unpredictably cause deeper tissue damage in some instances. A tissue temperature above $60^{\circ} \mathrm{C}$ is the coagulation temperature of many proteins; it is thus considered the threshold for tissue damage, since most biological effects which occur at temperatures higher than that are irreversible [7].

In endoscopy, normal saline is widely used for submucosal injection during advanced tissue resection to facilitate the removal of early carcinomas in the esophagus, stomach and intestine with less risk of perforation or unintended thermal damage to the muscle layer. This can be achieved using a needle and syringe or a high-pressure needleless injection system [8]. More recently, this concept has been applied to mucosal APC ablation of angiodysplasias and early Barrett's neoplasia. A number of ex vivo studies have demonstrated the ability of a submucosal normal saline cushion to limit deeper thermal damage of the GI tract after APC application [9-12]. Furthermore, saline injection prior to APC has been advantageously applied to increase the efficacy and decrease the stricture rate in the endoscopic therapy of Barrett's neoplasia [13].

The primary aim of this systematic ex vivo study was to compare the submucosal fluid cushions of 4 alternative injection fluids with the standard $0.9 \%$ sodium chloride solution as gold standard, in terms of thermal damage protection of the muscle layer of the esophagus, stomach and rectum during mucosal APC application. Secondly, we aimed to determine the minimum volume of injection fluid required to prevent unwanted thermal damage to the deeper tissue layers of the GI tract. Unwanted thermal damage occurs, according to our definition, if tissue is heated above $60^{\circ} \mathrm{C}$ (coagulation temperature of most biological tissues [7]) starting from body temperature $\left(37^{\circ} \mathrm{C}\right)$, and if tissue is heated above $45^{\circ} \mathrm{C}$ starting from room temperature $\left(22-25^{\circ} \mathrm{C}\right)$. Thirdly, we aimed to determine whether the final temperature inside the fluid cushion after APC application is dependent on the initial temperature of the injection fluid (room temperature vs. body temperature).

\section{Materials and methods}

\section{Animal model}

All testing was carried out in an ex vivo porcine model (internal review board approval was not required). The stomach (fundus), esophagus and rectum of domestic pigs were obtained from a local slaughterhouse and stored frozen. On the day of testing, the tissue was thawed in a $25^{\circ} \mathrm{C}$ water bath, then rinsed with lukewarm water to remove large contaminants. All experiments were then performed at room temperature (22$25^{\circ} \mathrm{C}$ ) and at $37^{\circ} \mathrm{C}$ in an incubator simulating human body temperature. Five commercially available injection fluids were tested: normal saline, $0.9 \%$ sodium chloride solution (B. Braun
Melsungen AG, Germany); Glyceol, a 10\% glycerol-5\% fructose solution (Chugai Pharmaceuticals Co. Ltd., Japan); $4 \%$ Gelafundin, a synthetic succinylated gelatin solution (B. Braun Melsungen AG, Germany); 10\% Voluven, a synthetic hydroxyethyl starch solution (Fresenius Kabi Germany GmbH); and Eleview, a proprietary solution of synthetic polymers (COSMO Pharmaceuticals, Italy). All alternative fluids have a higher viscosity and a similar electrical impedance compared to normal saline $[14,15]$.

\section{Methods for tissue elevation}

A standard 23-G catheter injection needle (Olympus, NM201L-0423), in conjunction with a 10-mL standard syringe (B. Braun, Germany), was used for mucosal elevation. The application angle was $30^{\circ}$. Submucosal injection was performed with $0,1,2,3,4$ and $5 \mathrm{~mL}$ of fluid for each injection fluid and in all 3 types of tissue (Fig. 1).

\section{Physical parameters for the APC ablation}

After elevation as described above, the tissue was treated with APC using the VIO300D electrosurgical unit (ERBE Elektromedizin $\mathrm{GmbH}$ ) at the following setting: PULSED APC Effect 2. A standard flexible APC probe (axial, length $220 \mathrm{~mm}$, outer diameter $2.3 \mathrm{~mm}$, reference no. 20132-177) was utilized and placed at a precise distance of $3 \mathrm{~mm}$ above the elevated tissue surface at a $90^{\circ}$ angle and activated for $3 \mathrm{sec}$ each time. A 3-sec interval of treatment was chosen to simulate the usual clinical application (Fig. 2). Power settings of $30 \mathrm{~W}, 60 \mathrm{~W}, 90 \mathrm{~W}$ and $120 \mathrm{~W}$ were sequentially tested in esophagus, stomach and rectum.

\section{Measurement of temperature inside the protective fluid cushion on top of the muscle layer}

Immediately after the APC ablation, a temperature sensor was passed through the inner part of an intravenous indwelling

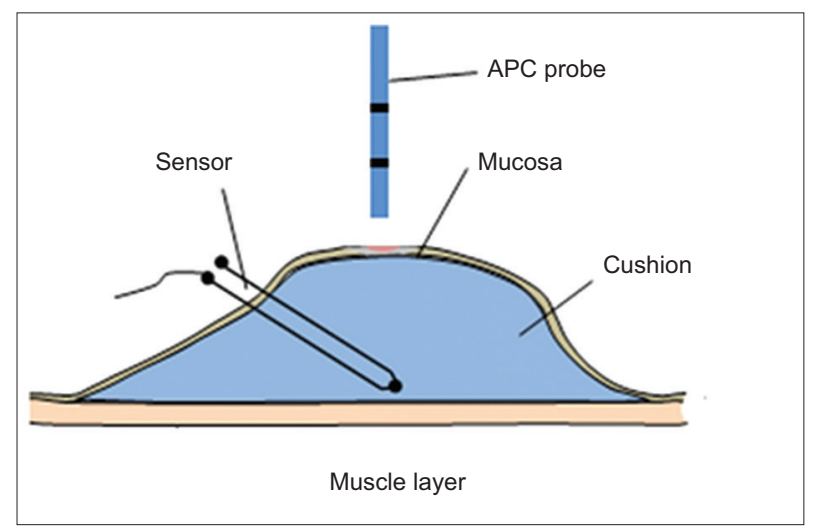

Figure 1 Injection of $\mathrm{NaCl} 0.9 \%$ vs. Glyceol in stomach (fundus). Injected with $23-\mathrm{G}$ cannula. Volume $5 \mathrm{~mL}$ each APC, argon plasma coagulation 


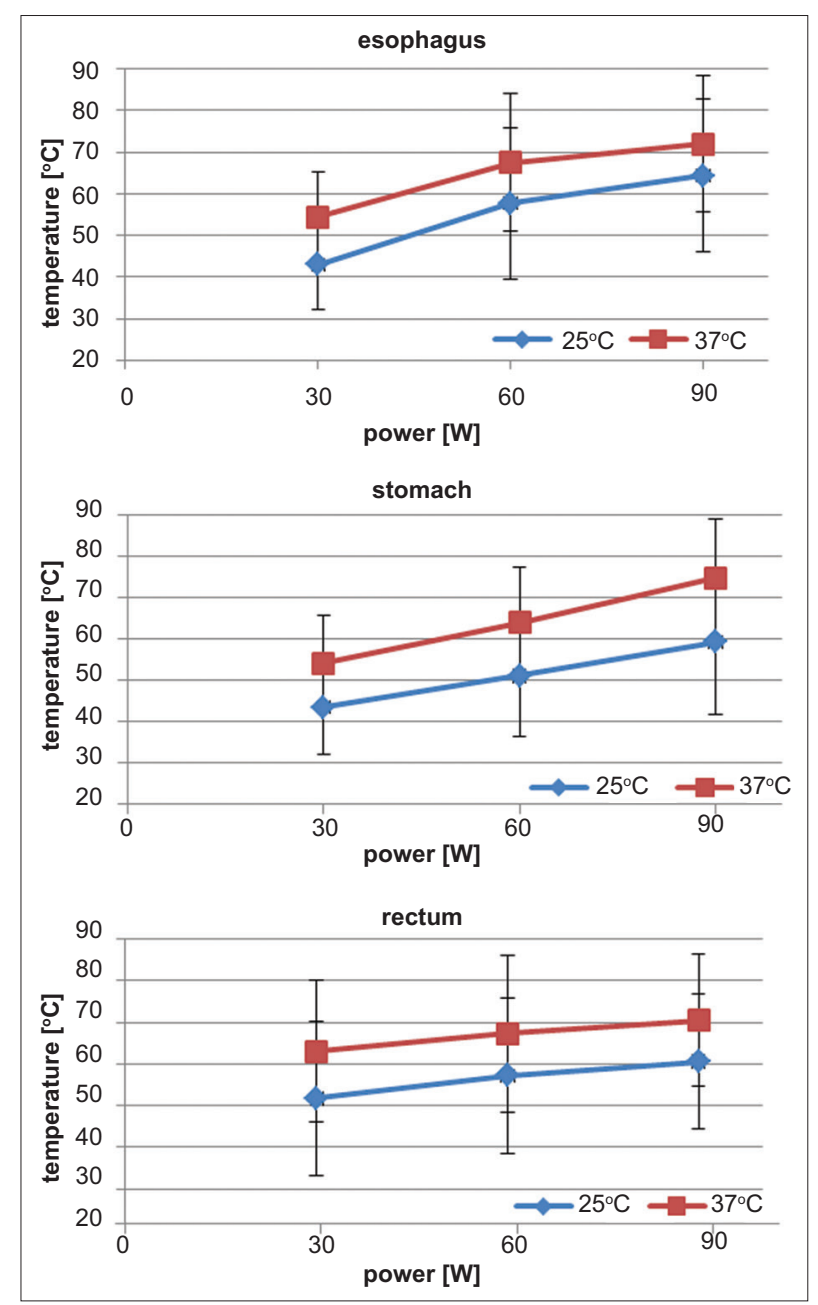

Figure 2 Argon plasma coagulation (APC): Top view (A) and sectional view (B): Stomach (corpus); Injection solution: Gelafundin, $5 \mathrm{~mL}$; APC: Forced APC, $50 \mathrm{~W}$, Flow (Ar) $1 \mathrm{~L} / \mathrm{min}$; $\mathrm{t}=2 \mathrm{sec}$, Distance $3 \mathrm{~mm}$

cannula (20G, Braunüle, B. Braun Melsungen AG, Germany) and positioned inside the fluid cushion just on top of the muscle layer (Fig. 3). The temperature was then recorded with a digital measuring device (Testo 950, Testo AG, Germany). In the case of tissue at body temperature $\left(37^{\circ} \mathrm{C}\right)$, unwanted tissue heating was defined as a temperature of $60^{\circ} \mathrm{C}$, and in the case of tissue at room temperature $\left(22-25^{\circ} \mathrm{C}\right)$ unwanted heating was defined to be $45^{\circ} \mathrm{C}$.

\section{Statistical analysis}

All analyses were performed by using PRISM version 6.0 (Graphpad Software Inc., La Jolla, USA). Data were collected and analyzed by means of descriptive statistics (mean and standard deviation) as well as hypothesis testing. Normality of distribution was verified using the Kolmogorov-Smirnov test. Differences between normally distributed, independent quantitative data were analyzed using one-way ANOVA, following Dunnett's multiple comparisons test. For non- normally distributed data the Kruskal-Wallis test was used. P-values less than 0.05 were considered statistically significant.

\section{Results}

\section{Temperature inside the fluid cushion}

First, we compared the temperatures inside the fluid cushion after $3 \mathrm{sec}$ of APC application for injections with the tissue at room temperature $\left(22-25^{\circ} \mathrm{C}\right)$, then at body temperature $\left(37^{\circ} \mathrm{C}\right)$, using normal saline as injection fluid. Fig. 4 shows the results for esophagus (4A), stomach (4B), and rectum (4C). Comparing the 2 starting temperatures, the highest average increase was measured in the case of the stomach at $90 \mathrm{~W}$. Here, the final temperature was $59.2 \pm 17.7^{\circ} \mathrm{C}$ when the initial fluid temperature was $25^{\circ} \mathrm{C}$, and $74.7 \pm 14.1^{\circ} \mathrm{C}$ when the initial tissue temperature was $37^{\circ} \mathrm{C}(\mathrm{P}=0.0067)$. Thus, the increase in temperature due to the use of tissue at body temperature instead of tissue at room temperature is on average not more than $15.5^{\circ} \mathrm{C}$ at an application time of $3 \mathrm{sec}$.

The highest temperature inside the fluid cushion (initial tissue temperature $\approx 25^{\circ} \mathrm{C}$ ) of all 5 injection fluids in relation to the power setting $(\mathrm{W})$, injection volume $(\mathrm{mL})$ and the type of tissue is shown in esophagus (Fig. 5), stomach (Fig. 6), and rectum (Fig. 7). Without prior tissue elevation (injection volume $0 \mathrm{~mL}$ ), the temperature on top of the muscle layer reached around $80^{\circ} \mathrm{C}\left( \pm 5^{\circ} \mathrm{C}\right)$ at maximum power settings of 90 $120 \mathrm{~W}$ for all intended fluid injections and for all tissue types. Virtually the same results, exhibiting no relevant differences in temperature measurements for normal saline, Glyceol, Gelafundin, Voluven and Eleview, were found for equal power settings and equal injection volumes with regard to all 3 types of tissue.

Fig. 2-4 also illustrate increasing temperatures with increasing power settings for equal fluid volumes. Here, the increasing temperature gradient is smaller in the case of larger amounts of injection fluid. Decreasing temperature was recorded with increasing volumes of injection fluid. With an injection volume of $3 \mathrm{~mL}$ (up to $90 \mathrm{~W}$ ) and $4 \mathrm{~mL}$ (up to $120 \mathrm{~W}$ ), the average temperature inside the fluid cushion stayed below $45^{\circ} \mathrm{C}$ (red line in Fig. 2-4) in all tissues investigated. We used the $45^{\circ} \mathrm{C}$ line in the case of fluids initially at room temperature because it corresponds to the $60^{\circ} \mathrm{C}$ coagulative limit of injections of fluid at body temperature.

\section{Discussion}

Our experiments demonstrate that submucosal cushioning can protect the muscle layer from thermal injury during mucosal APC, irrespectively of the injection fluid. Furthermore, the total volume injected is the main factor in this protective effect, as opposed to the type of fluid utilized or the location of treatment within the GI tract. 


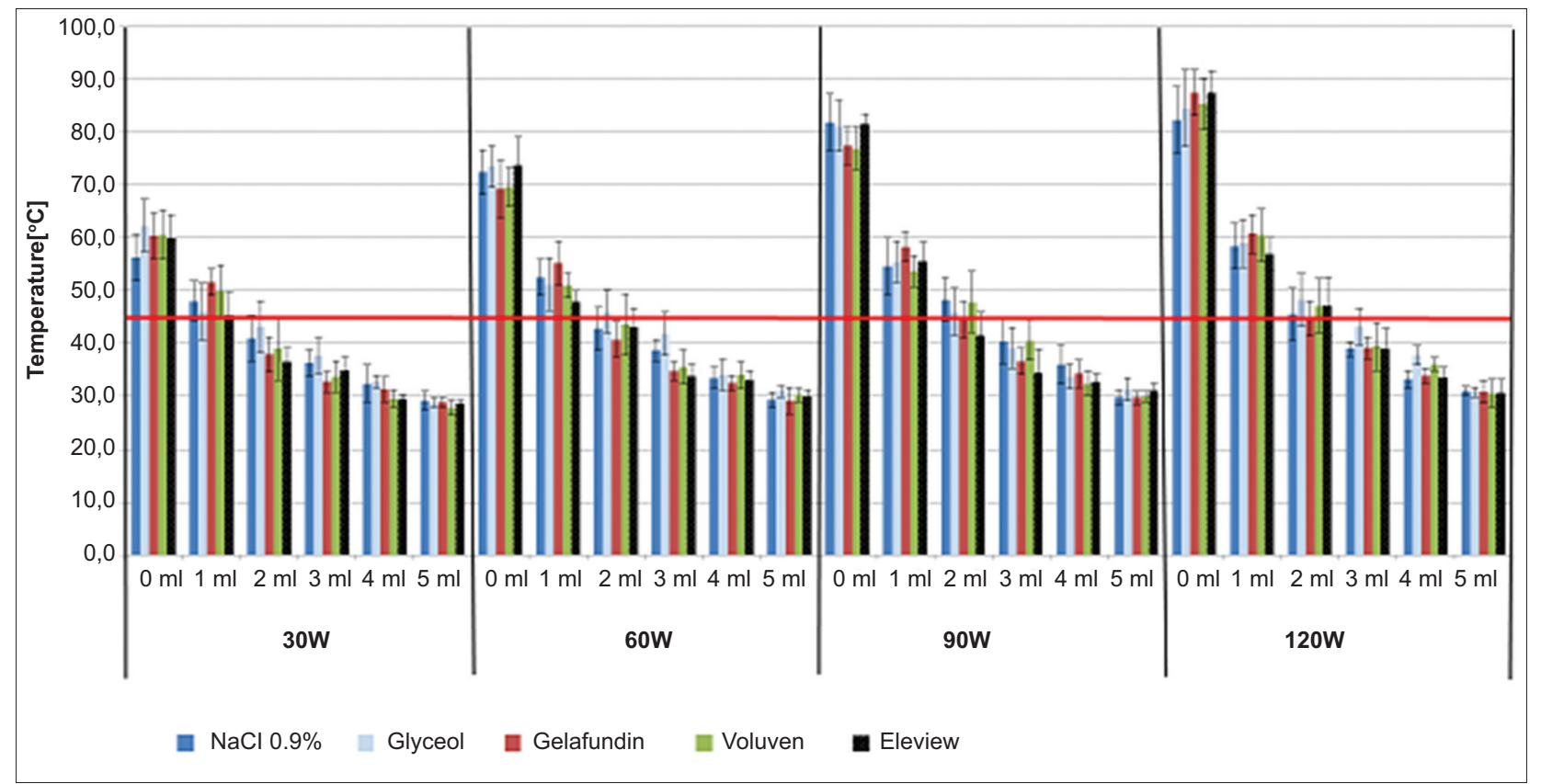

Figure 3 Experimental setup for measurement of temperature inside the protective fluid cushion on top of the muscle layer

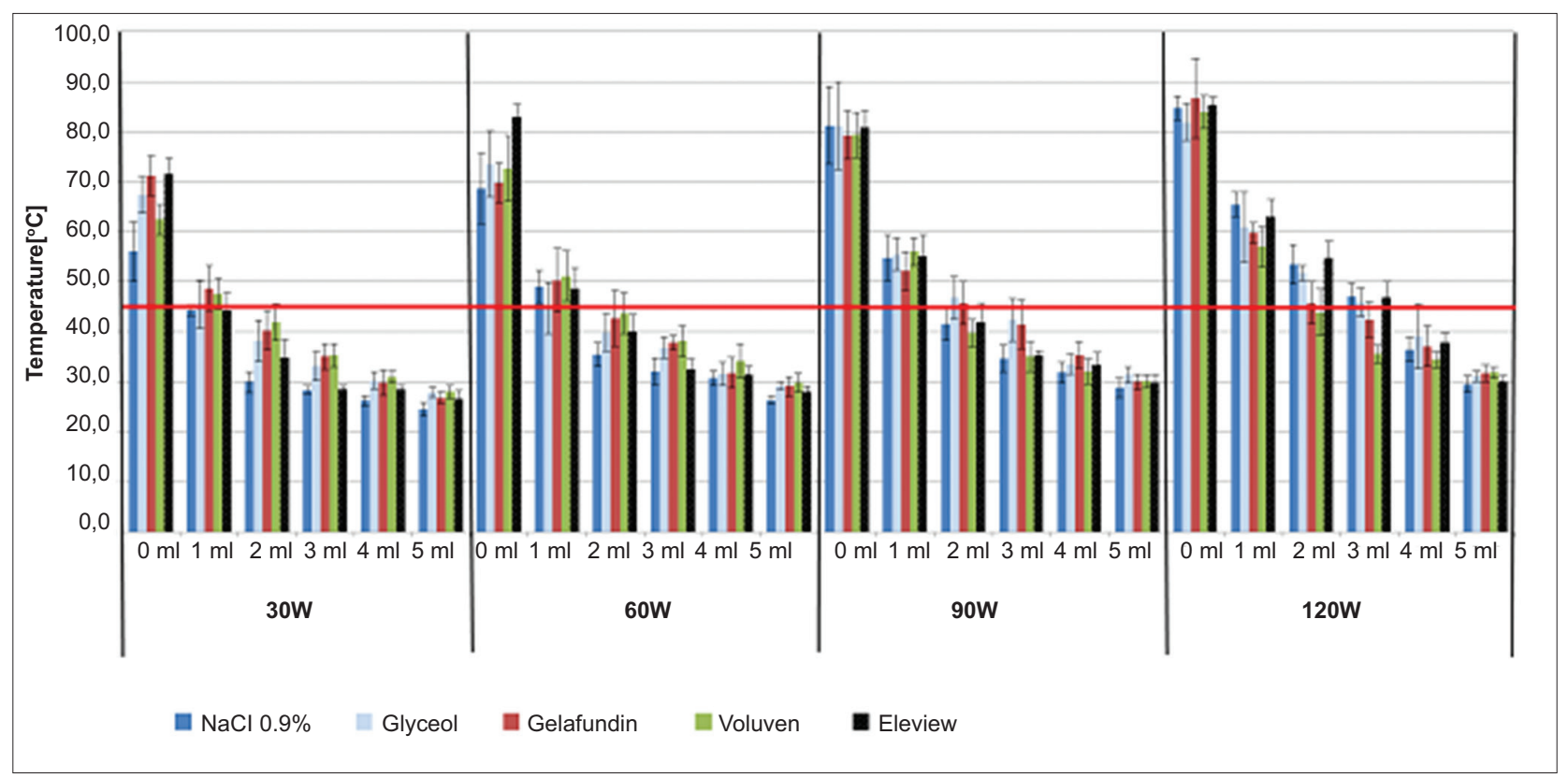

Figure 4 Comparison of the final temperature of the fluid cushion in stomach (A), rectum (B) and esophagus (C), using normal saline as injection fluid with different initial tissue temperatures (blue $25^{\circ} \mathrm{C}$, red $37^{\circ} \mathrm{C}$ ) at different settings of electrical power $(30,60$ and $90 \mathrm{~W})$. The temperatures shown are mean values from measurements with injection volumes of 0,1 and $2 \mathrm{~mL}$

Although APC of the GI mucosa is felt to cause only superficial thermocoagulation in clinical applications, adverse events due to deeper thermal injury can occur [16,17]. The addition of submucosal fluid to the target area prior to APC may further improve its safety profile and is quite simple and economical to employ. To underscore this principle, an interesting experiment by Fujishiro et al [18] tested the immediate and delayed effects of the addition of normal saline submucosal injection prior to varying duration and degrees of APC of the stomach in a live porcine model. In the animal sacrificed immediately after APC, no differences were found in the pattern or degree of injury in the non-injected versus injected APC sites on either macroscopic or microscopic examination. However, in the pig sacrificed 1 week later, the non-injected APC site showed a deep ulceration extending to the muscle layer, whereas the injected site had only a superficial 


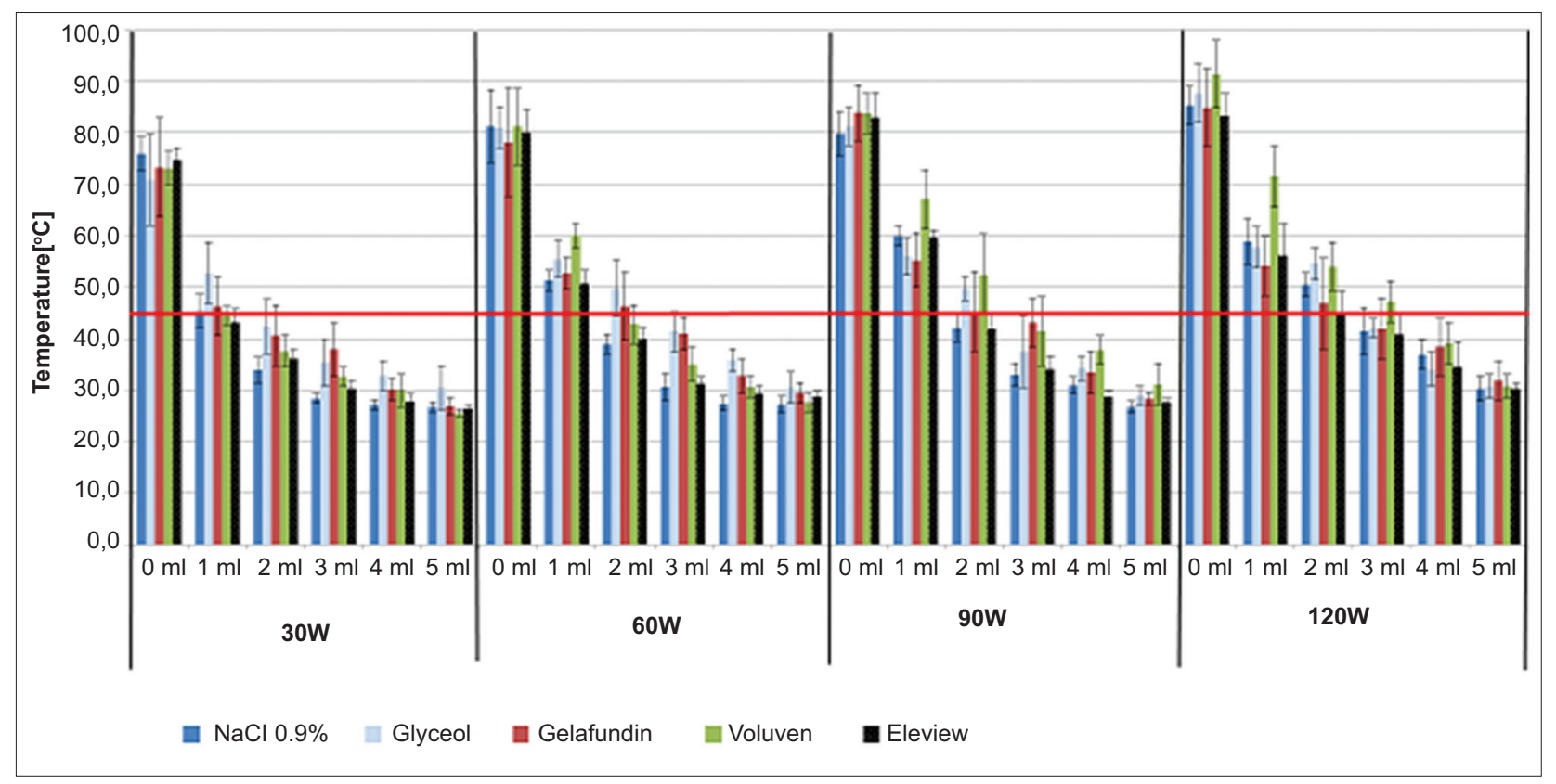

Figure 5 Esophagus temperature inside the fluid cushion after $3 \mathrm{sec}$ of PULSED argon plasma coagulation E2 using power settings 30, 60, 90 and $120 \mathrm{~W}$ and different injection volumes $(0-5 \mathrm{~mL})$. The initial temperature of the tissue was $25^{\circ} \mathrm{C}$

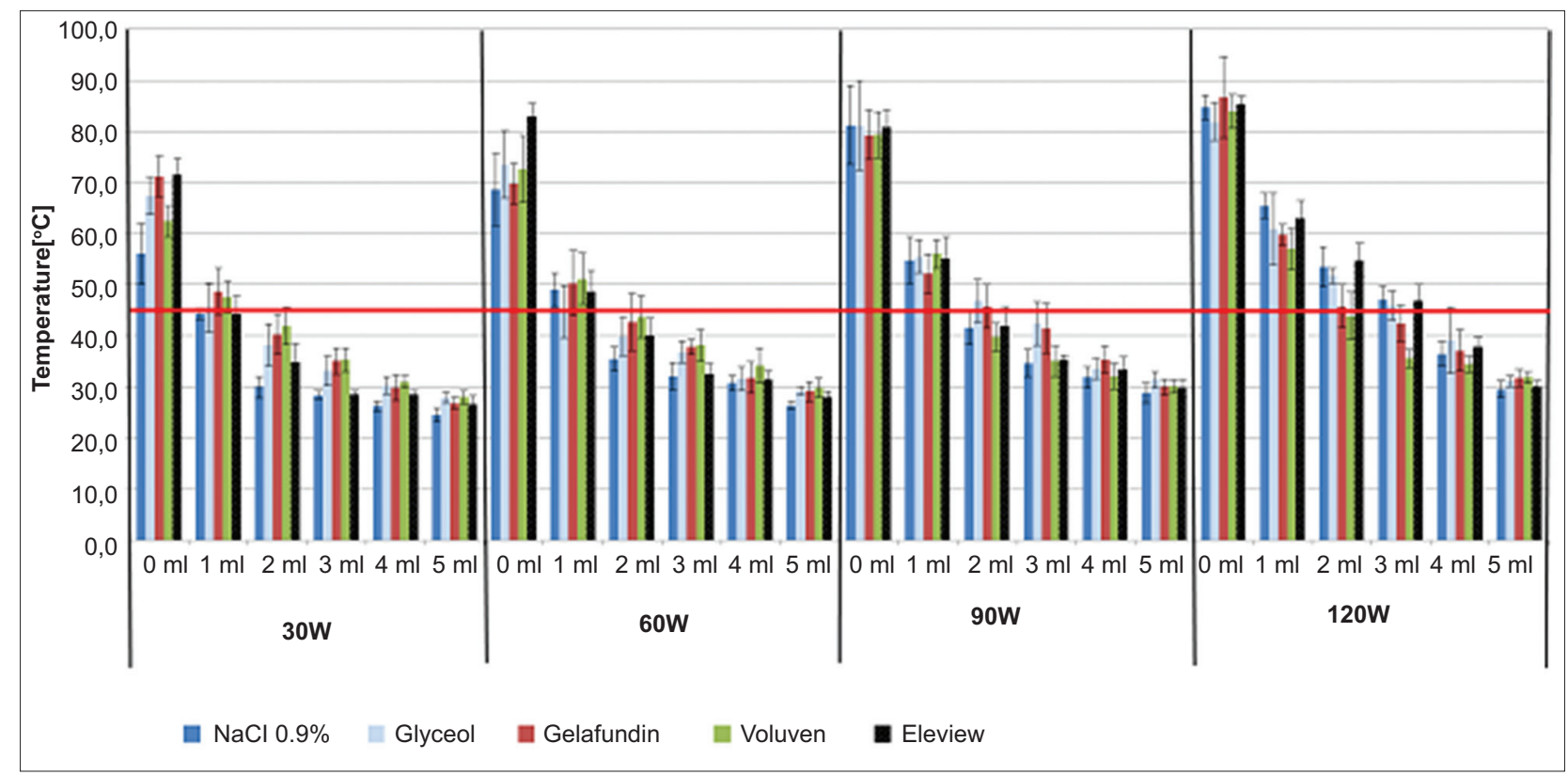

Figure 6 Stomach temperature inside the fluid cushion after $3 \mathrm{sec}$ of PULSED argon plasma coagulation E2 using power settings 30, 60, 90 and $120 \mathrm{~W}$ and different injection volumes $(0-5 \mathrm{~mL})$. The initial temperature of the tissue was $25^{\circ} \mathrm{C}$

submucosal injury [16]. Prior experiments by this and other groups also indicate that a submucosal saline cushion mitigates thermal injury to the muscle layer in all areas of the GI tract $[9,11]$

In an ex vivo study, Manner et al [10] demonstrated that introducing a saline fluid cushion reduces the coagulation depth by half in comparison with direct mucosal APC in pig esophagus [10]. They theorized that this would lead to a reduced stricture rate if this method was employed to treat Barrett's neoplasia. Indeed, this appeared to be the case in a subsequent human pilot study of so-called hybrid-APC for the treatment of residual non-dysplastic Barrett's after endoscopic resection of early Barrett's neoplasia [10]. Of the 60 patients treated, only one developed a symptomatic stricture $(2 \%)$, compared to a rate of $4-9 \%$ in the previously published literature $[5,6]$.

Furthermore, submucosal injection may allow higher power settings to be safely used, which may improve the efficacy of APC, particularly in treating superficial neoplasia. This was 


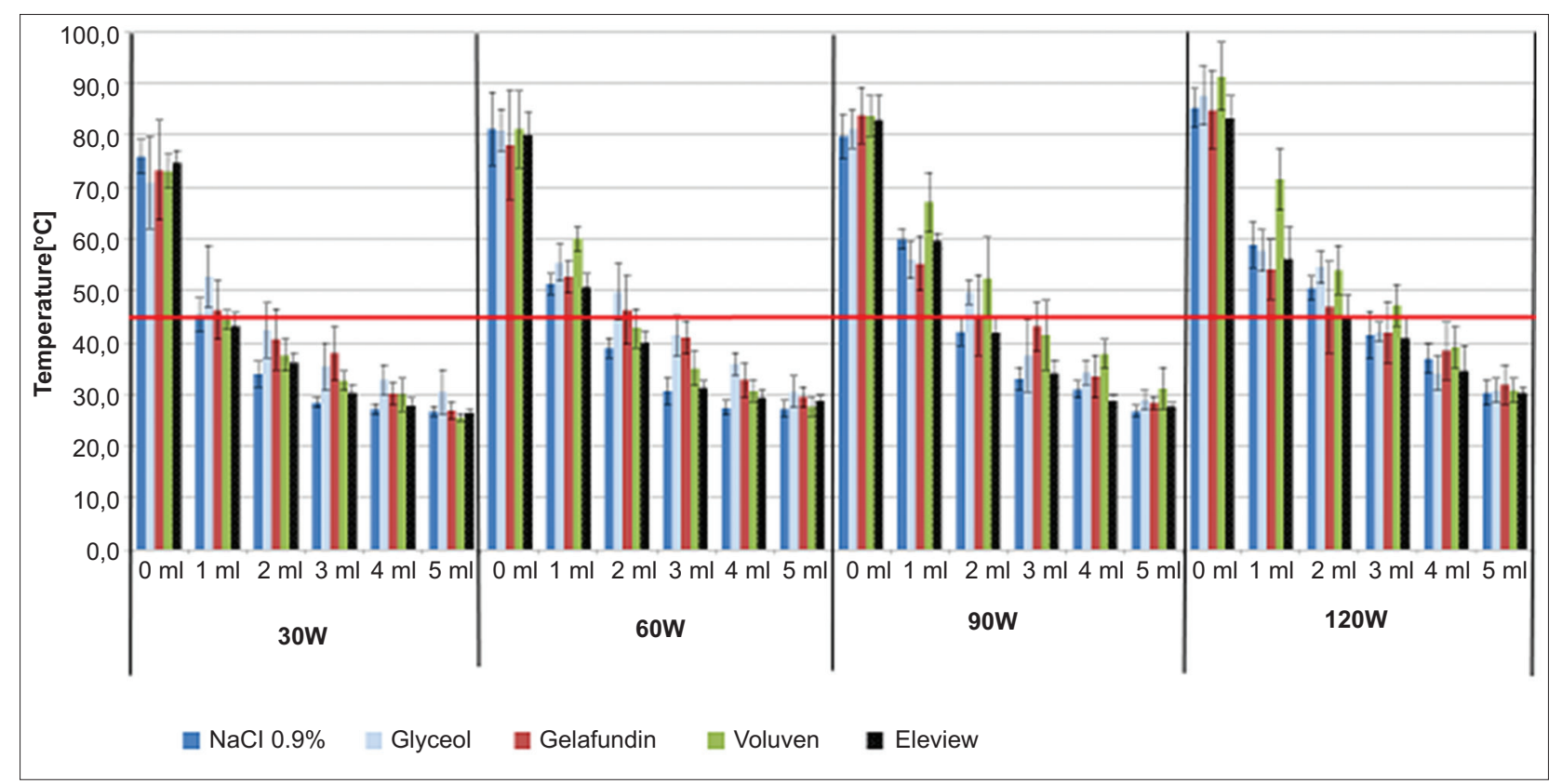

Figure 7 Rectum temperature inside the fluid cushion after $3 \mathrm{sec}$ of PULSED argon plasma coagulation E2 using power settings 30, 60, 90 and 120 $\mathrm{W}$ and different injection volumes $(0-5 \mathrm{~mL})$. The initial temperature of the tissue was $25^{\circ} \mathrm{C}$

shown in the Barrett's eradication trial by Manner et al, in which application of 50-60 W of hybrid-APC resulted in a $96 \%$ complete remission rate of intestinal metaplasia [13]. Shimizu et al also showed (in an abstract) this hybrid-APC technique to be safe and effective in wide-field ablation of Barrett's esophagus [19]. Another study by Gong et al in ex vivo human stomachs with a view to treating early gastric neoplasia showed that complete mucosal necrosis via APC without damaging the muscle layer was only achievable with prior submucosal saline injection [12]. The proportion of lesions with necrosis of the submucosa and muscle layer was significantly higher in the non-injection group. Furthermore, only 1 lesion in the submucosal injection group showed any muscularis propria damage (at the most extreme setting of $80 \mathrm{~W}$ applied for $25 \mathrm{sec})$.

One might predict that injection solutions with varying viscosities and chemical components could confer different insulating properties to the submucosal fluid cushion. However, our experiments show that this does not appear to be the case. Irrespective of the tissue type, there was no significant difference in the final temperature of the fluid cushion, for equal power settings and injection volumes, between any of the 5 injection fluids tested. Perhaps the magnitude of the thermal effect of APC ablation far outweighs any differences in the insulating effects between the constituents of each fluid.

In our experiments, not unexpectedly, the initial temperature of the tissue directly correlated with the final temperature inside the fluid cushion after APC. The measured temperature starting from body temperature was on average $15^{\circ} \mathrm{C}$ higher than when starting from room temperature. Therefore, measurements based on body temperature must be evaluated differently from those based on room temperature. In the case of measurements based on body temperature, heating the tissue above the coagulation temperature of $60^{\circ} \mathrm{C}$ corresponds to irreversible unwanted tissue heating [7]. In the case of measurement based on room temperature, the abovementioned additional heating due to body temperature must be taken into account. This means that unwanted tissue heating occurs at a measured temperature of $45^{\circ} \mathrm{C}$ or higher.

The most pertinent finding from our experiments is the minimum volume of injection fluid required to prevent unwanted thermal injury. For a 3-sec APC application up to $90 \mathrm{~W}$, at least $3 \mathrm{~mL}$ of injection fluid is required to keep the fluid temperature below the threshold for thermal injury $\left(60^{\circ} \mathrm{C}\right)$ to deeper tissues. An additional $1 \mathrm{~mL}$ of injection $(4 \mathrm{~mL}$ total) allows up to $120 \mathrm{~W}$ of APC to be safely applied for $3 \mathrm{sec}$. Larger injection volumes therefore may allow higher power settings and/or a longer duration of treatment (i.e., $>3 \mathrm{sec}$ ) to be used safely.

These experiments are limited due to the ex vivo and nonhuman nature of the study; thus, they may underestimate the effects of APC on in vivo human tissue. Care was taken to ensure the porcine tissue was completely thawed and the target tissue areas remained at the intended normal body temperature before treatments were applied. We also relied on the final fluid temperature as a surrogate for thermal damage and did not obtain histology specimens for direct examination. In addition, only a limited number of lesions were created. However, the results obtained were very consistent across all parameters (anatomic location, power setting, volume of injection fluid). Ideally, the results of these experiments should be verified in human tissue, although the practicalities of acquiring fresh ex vivo specimens are a barrier.

In conclusion, to prevent unintended muscle layer injury of the GI tract during standard mucosal ablation with APC, we recommend that a minimum of $3 \mathrm{~mL}$ of fluid be injected into 
the submucosa prior to treatment (or at least $4 \mathrm{~mL}$ if $>90 \mathrm{~W}$ power is employed). The different injection fluids are equally effective in protecting deeper tissue layer. Adherence to these parameters is likely to improve the safety profile of mucosal APC treatment by further reducing the possibility of deep tissue injury or luminal perforation.

\section{Summary Box}

\section{What is already known:}

- The most feared argon plasma coagulation (APC)related adverse events (e.g., perforation) may be due to thermal damage to the muscle layer during mucosal application

- APC-related thermal damage may be avoided by creating a fluid cushion within the submucosal layer

- There are no data about the minimum injection volume needed or the ideal injection fluid to prevent thermal damage to the muscle layer during APC ablation

\section{What the new findings are:}

- Normal saline and 4 commercially available submucosal injection fluids possess similar thermal protective effects

- The protective effect was confirmed in all the locations at equal injection volumes and power settings

- A minimum injection volume of $3 \mathrm{~mL}$ is recommended if less than $90 \mathrm{~W}$ power will be utilized over $3 \mathrm{sec}$

\section{References}

1. Grund KE, Storek D, Farin G. Endoscopic argon plasma coagulation (APC) first clinical experiences in flexible endoscopy. Endosc Surg Allied Technol 1994;2:42-46.

2. Wahab PJ, Mulder CJ, den Hartog G, Thies JE. Argon plasma coagulation in flexible gastrointestinal endoscopy: pilot experiences. Endoscopy 1997;29:176-181.

3. Sami SS, Al-Araji SA, Ragunath K. Review article: gastrointestinal angiodysplasia - pathogenesis, diagnosis and management. Aliment Pharmacol Ther 2014;39:15-34.

4. Farooq FT, Wong RC, Yang P, Post AB. Gastric outlet obstruction as a complication of argon plasma coagulation for watermelon stomach. Gastrointest Endosc 2007;65:1090-1092.

5. Schulz H, Miehlke S, Antos D, et al. Ablation of Barrett's epithelium by endoscopic argon plasma coagulation in combination with high-dose omeprazole. Gastrointest Endosc 2000;51:659-663.

6. Pereira-Lima JC, Busnello JV, Saul C, et al. High power setting argon plasma coagulation for the eradication of Barrett's esophagus. Am J Gastroenterol 2000;95:1661-1668.

7. Repici A, Maselli R, Carrara S, Anderloni A, Enderle M, Hassan C. Standard needle versus needleless injection modality: animal study on different fluids for submucosal elevation. Gastrointest Endosc 2017;86:553-558.

8. Ansari MA, Erfanzadeh M, Mohajerani E. Mechanisms of lasertissue interaction: II. tissue thermal properties. J Lasers Med Sci 2013;4:99-106.

9. Norton ID, Wang L, Levine SA, et al. Efficacy of colonic submucosal saline solution injection for the reduction of iatrogenic thermal injury. Gastrointest Endosc 2002;56:95-99.

10. Manner H, Neugebauer A, Scharpf M, et al. The tissue effect of argon-plasma coagulation with prior submucosal injection (hybrid-APC) versus standard APC: a randomized ex-vivo study. United European Gastroenterol J 2014;2:383-390.

11. Fujishiro M, Yahagi N, Nakamura M, et al. Submucosal injection of normal saline may prevent tissue damage from argon plasma coagulation: an experimental study using resected porcine esophagus, stomach, and colon. Surg Laparosc Endosc Percutan Tech 2006; 16:307-311.

12. Gong EJ, Ahn JY, Jung HY, et al. Effects of argon plasma coagulation on human stomach tissue: an ex-vivo study. J Gastroenterol Hepatol 2017;32:1040-1045.

13. Manner H, May A, Kouti I, Pech O, Vieth M, Ell C. Efficacy and safety of hybrid-APC for the ablation of Barrett's esophagus. Surg Endosc 2016;30:1364-1370.

14. Repici A, Wallace M, Sharma P, et al. A novel submucosal injection solution for endoscopic resection of large colorectal lesions: a randomized, double-blind trial. Gastrointest Endosc 2018;88:527-535.

15. Spadaccini M, Hassan C, Maselli R, et al. Efficacy and safety of SIC$8000\left(\right.$ Eleview $\left.^{\circ}\right)$ for submucosal injection for endoscopic mucosal resection and endoscopic submucosal dissection in an in vivo porcine model. Dig Liver Dis 2018;50:260-266.

16. Naimimohasses S, Lavelle A, Kelleher TB. Life-threatening complication of routine argon plasma photocoagulation. Gastroenterology 2014;147:751-753.

17. Sharma P, Wani S, Weston AP, et al. A randomised controlled trial of ablation of Barrett's oesophagus with multipolar electrocoagulation versus argon plasma coagulation in combination with acid suppression: long term results. Gut 2006;55:1233-1239.

18. Fujishiro M, Kodashima S, Ono S, et al. Submucosal injection of normal saline can prevent unexpected deep thermal injury of argon plasma coagulation in the in vivo porcine stomach. Gut Liver 2008;2:95-98.

19. Shimizu T, Samarasena J, Fortinsky KJ, Chin MA, Chang KJ. Efficacy, safety and tolerance of hybrid-argon plasma coagulation for the treatment of Barrett's Esophagus: a single centre pilot study. Gastrointest Endosc 2018;87(6 Suppl 1):AB292. 